\title{
To the blessed memory of Mark Naumovich Berdichevsky
}

DOI: $10.1134 / \mathrm{S} 1069351311010113$

This special issue publishes selected papers presented at the 4th All-Russia Seminar-Workshop on the Electromagnetic Sounding of the Earth (Moscow, September 1-4, 2009). The Seminar-Workshop was organized by the Geoelectromagnetic Research Center of the Schmidt Institute of Physics of the Earth of the Russian Academy of Sciences (GEMRC IPE RAS) and the Section of Electromagnetic Research of the Council on the Problems of Physics of the Earth under the support of the Presidium of the Russian Academy of Sciences, the Branch of Geology, Geophysics, Geochemistry and Mining Sciences (Russian Academy of Sciences), and the Russian Foundation for Basic Research.

The Seminar-Workshop discussed the following most topical problems of modern geoelectrics:

— deep electromagnetic sounding;

- modeling and inversion of electromagnetic data;

- electromagnetic research in seismically active, volcanic, and geothermal regions;

- environmental studies and prospecting for mineral resources.

The central topic of the 4th Seminar-Workshop was the joint interpretation of the electromagnetic and other geophysical data. For full coverage of this topical issue, the lectures were delivered by the leading specialists representing institutes of the Russian Academy of Sciences and commercial geophysics research institutions: P.S. Babayants, Dr. Sci. (Phys.-Math.), V.V. Belyavskii, Dr. Sci. (Tech.), A.A. Nikitin, Dr. Sci. (Phys.-Math.), N.I. Pavlenkova, Dr. Sci. (Phys.Math.), A. Ya. Sidorin, Cand. Sci. (Phys.-Math.), V.V. Spichak, Dr. Sci. (Phys.-Math.), and E.N. Cheremisina, Dr. Sci. (Phys.-Math.).

Papers included in the special issue consider new approaches to the solution of forward and inverse problems of geoelectrics. Methods of interpretation based on a combined analysis of electromagnetic, seismic, and geothermal data were developed. Methodological and practical issues of electromagnetic sounding employing natural and controlled sources and taking into account the effects of induced polarization and three-dimensional media were considered.

On the whole, there are grounds to hope that publishing this special issue of the Journal will make a noticeable contribution to the theory of electromagnetic sounding of the Earth.

$$
\text { V.V. Spichak, Dr. Sci. (Phys.-Math.) }
$$

